
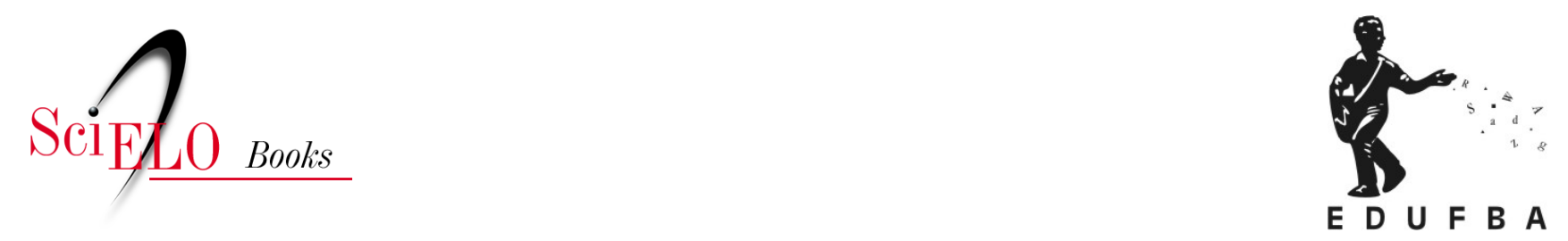

\title{
Análise sócio-histórica das políticas de saúde algumas questões metodológicas da abordagem bourdieusiana
}

\author{
Ligia Maria Vieira-da-Silva \\ Sonia Cristina Lima Chaves \\ Monique Azevedo Esperidião \\ Sandra Garrido de Barros \\ Jamacy Costa Souza
}

\section{SciELO Books / SciELO Livros / SciELO Libros}

VIEIRA-DA-SILVA, L.M., CHAVES, S.C.L., ESPERIDIÃO, M.A., BARROS, S.G., and SOUZA, J.C. Análise sócio-histórica das políticas de saúde: algumas questões metodológicas da abordagem bourdieusiana. In: TEIXEIRA, C.F., comp. Observatório de análise política em saúde: abordagens, objetos e investigações [online]. Salvador: EDUFBA, 2016, pp. 15-40. ISBN 978-85-232-2021-1. https://doi.org/10.7476/9788523220211.0002.

All the contents of this work, except where otherwise noted, is licensed under a Creative Commons Attribution 4.0 International license.

Todo o conteúdo deste trabalho, exceto quando houver ressalva, é publicado sob a licença Creative Commons Atribição 4.0. 
Ligia Maria Vieira-da-Silva, Sonia Cristina Lima Chaves, Monique Azevedo Esperidião, Sandra Garrido de Barros e Jamacy Costa Souza

\section{ANÁLISE SÓCIO-HISTÓRICA DAS POLÍTICAS DE SAÚDE algumas questões metodológicas da abordagem bourdieusiana}

\section{Introdução}

Qual a importância dos estudos sócio-históricos para a análise contemporânea das políticas de saúde? Sobretudo quando confrontados com demandas relacionadas com o monitoramento e acompanhamento de políticas, seja no curso de sua implementação, seja num horizonte de tempo considerado como atual ${ }^{1}$ Em primeiro lugar, a história serve ao pesquisador e ao gestor como proteção para evitar os problemas éticos e operacionais relacionados com a reinvenção da roda. Éticos em decorrência das implicações decorrentes

O momento atual, no caso, é o período compreendido entre o início do projeto (2014) e sua conclusão, prevista para 2018. A própria formulação do que seria o momento atual já encerra um passado. 0 projeto iniciou-se em 2014, que já é um passado recente, e deverá encerrar-se em 2018, no momento um futuro que progressivamente vai convertendo-se em passado. 
da atribuição indevida de originalidade e operacionais porque políticas e programas de saúde já testados, em outros momentos históricos, trazem consigo lições relacionadas com as razões do seu sucesso ou fracasso.

As características do processo de gestão, que requerem frequentemente a tomada de decisões urgentes, constituem-se em ambiente propício para a mobilização do senso comum ou do senso comum douto, o que cria no gestor a ilusão da inovação. Assim, a introdução do Programa de Saúde da Família (PSF), em 1994, pode ser considerada como uma inovação decorrente de iniciativas específicas daquele momento histórico. Contudo, uma análise mais cuidadosa pode revelar que as principais ideias já estavam contidas nos programas de medicina familiar dos anos 1950. Dessa forma, a construção de uma problemática de pesquisa já passa a interrogar quais as especificidades de cada momento histórico e encontrar pistas na comparação, na qual semelhanças e diferenças podem auxiliar na explicação dos fenômenos.

Uma segunda razão está relacionada com as indicações que a análise histórica fornece para o desenho de cenários futuros. Não apenas a interpretação das séries temporais que indicam tendências, mas também os exemplos das possibilidades e das impossibilidades ligadas a determinadas conjunturas históricas. Essas questões têm sido trazidas por historiadores e pesquisadores de outras disciplinas. A resposta à pergunta "A História importa?" tem sido afirmativa para diversos autores, tanto no que diz respeito à análise das políticas públicas em geral (HOCHMAN, 2013), como para as políticas de saúde em particular. (STEVENS; ROSENBERG; BURNS, 2006)

Contudo, é o sociólogo francês Pierre Bourdieu um daqueles que fundamentam de forma mais radical a importância da história para o conhecimento do mundo social, inicialmente destacando a história como recurso poderoso para a ruptura com o senso comum, operação necessária para a construção do conhecimento científico (BOURDIEU; CHAMBOREDON; PASSERON, 1999), e posteriormente como démarche necessária para a análise dos diversos cam- 
pos sociais. (BOURDIEU, 1996a, 2012) Para esse autor, o estudo sobre a gênese, que não se confunde com a busca das origens, permite escapar da ilusão do nominal. Em outras palavras, uma instituição ou mesmo uma política cujo nome se mantém ao longo da história pode corresponder a fenômenos distintos. A compreensão do que seria saúde da família dos anos 1950 pode ser completamente diferente do significado do programa que tem esse mesmo nome nos anos 1990. Da mesma forma, o Ministério da Saúde (MS) dos anos 1970 guarda identidades e diferenças com o MS dos anos 2000. O inverso também pode ocorrer: muda-se o nome e mantêm-se a mesma estrutura. Como exemplo, durante o governo Sarney, o Programa de Nutrição e Saúde (PNS), criado em 1975, passou a chamar-se Programa de Suplementação Alimentar (PSA), sem que diferenças significativas houvesse entre eles. (SOUZA, 1999)

Em segundo lugar, a análise histórica permite apreender a lógica das rupturas, das transformações, bem como as continuidades, as idas e vindas dos processos históricos. ${ }^{2}$ Uma das mais importantes contribuições dos estudos históricos apontada por aquele autor está na possibilidade de evitar o fenômeno, por ele denominado, de amnésia da gênese. No momento da emergência dos processos sociais é que os conflitos e as ambiguidades se expressam de forma explícita. Posteriormente, em decorrência das lutas e do desenvolvimento dos espaços sociais, determinados fenômenos, uma vez constituídos, passam despercebidos. (BOURDIEU, 2012) O estudo sobre a gênese do Programa de Alimentação do Trabalhador (PAT) revelouse como um caso exemplar desse efeito. Assim, o que no princípio era declaradamente um Programa de Incentivo Fiscal à Alimentação do Trabalhador (Pifat), sustentado, portanto, em uma Lei Tributária (BRASIL, 1976), passou a ser paulatinamente tratado apenas como um programa de alimentação do trabalhador, tanto nos artigos cientí-

Estudo sócio-histórico sobre a gênese da Saúde Coletiva, permitiu apreender a lógica da ruptura que possibilitou a criação da Saúde Coletiva brasileira. (VIEIRA-DA-SILVA, 2015; VIEIRA-DA-SILVA; PINELL, 2014) 
ficos como nos documentos oficiais, ainda que a lei continue em vigor. O resultado é a ocultação do que ele foi desde o seu início: preponderantemente uma política fiscal destinada à desoneração do custo de produção, mediante subsídio tributário às empresas que fornecessem alimentação aos trabalhadores do mercado formal, desde que regularmente inscritas junto ao Ministério do Trabalho (MT). (SOUZA, 2013) Nesse particular, a alimentação não é um fim da política, mas um meio a justificar uma renúncia fiscal.

Ainda como desdobramento dessa abordagem, está a possibilidade de apreender os componentes das estruturas e processos sociais que permitiram que a política tivesse sido formulada. A análise do espaço de possibilidades ao interior do qual os agentes realizaram suas trajetórias, ao mesmo tempo construindo o espaço e sendo por ele estruturados e limitados, permite identificar os possíveis realizados e os possíveis mortos. Ou seja, a análise da gênese de uma política propicia verificar as condições de possibilidade da sua emergência, em um dado momento histórico, e assim apreender os possíveis que são abertos com o evento investigado. (BOURDIEU, 2012) Alguns desses possíveis se realizam, outros não. Assim, apreender os possíveis mortos e as razões para o fechamento do espaço dos possíveis é um instrumento para os formuladores de políticas e gestores, particularmente aqueles comprometidos com as mudanças sociais.

O objetivo do presente capítulo é analisar algumas das questões teórico-metodológicas relevantes para o desenvolvimento de estudos sócio-históricos apoiados na teoria das práticas sociais de Bourdieu. Orientado também pela epistemologia desse mesmo autor, será apoiado em investigações concretas, já publicadas, procurando evitar, na medida do possível, a tentação das sínteses teóricas dissociadas do trabalho empírico.

\section{A construção do objeto}

Bourdieu, Chamboredon e Passeron (1999), apoiados na epistemologia de Bachelard (1996), ressaltam que o problema de inves- 
tigação é o resultado de uma construção que implica em rupturas com o senso comum. No caso da análise das políticas de saúde, o senso comum e o senso comum douto se apresentam como obstáculos ao desenvolvimento de investigações originais. Isso porque, frequentemente, os problemas de saúde e da gestão são confundidos com os problemas de investigação. Assim, a magnitude de um problema de saúde, a exemplo da mortalidade por neoplasias, para o qual existem políticas de saúde, não é um problema de pesquisa por si só. Uma série de perguntas precedem a construção desse problema como de pesquisa original, como pesquisa avaliativa ou como análise de política. Quais os tipos de neoplasia mais frequentes? As políticas formuladas para o controle desses tipos de neoplasias são capazes teoricamente de reduzir a mortalidade? Se a resposta é afirmativa, qual a cobertura? Se a cobertura é ampla, a qualidade do cuidado é adequada? A resposta a essas perguntas fornece informações importantes para a gestão dos serviços de saúde auxiliando no aperfeiçoamento das intervenções, porém não esclarecem os processos e as razões pelas quais as políticas foram formuladas bem como as implicações daí decorrentes para a sua operacionalização e possíveis efeitos.

Um outro grupo de perguntas poderia ser feito derivado da imagem-objetivo da abordagem do ciclo das políticas, inspiradas pela teoria da ação racional, nas suas variadas vertentes. Assim, as indagações sobre como o problema foi formulado e por quem, como entrou na agenda governamental, e como foi implementado são perguntas que auxiliam a descrever alguns dos processos relacionados com a formulação das políticas. A despeito da variedade de vertentes dessas abordagens, bem como a incorporação de elementos contraditórios e processuais em algumas dessas proposições (PINTO; VIEIRA-DASILVA; BAPTISTA, 2013), essas perspectivas de análise também não conseguem explicar os porquês do surgimento de determinadas políticas, em certos momentos históricos. Por exemplo, podem não esclarecer porque o câncer foi considerado como um flagelo social na França, entre as duas guerras mundiais, no século XX, em um momento onde sua magnitude não era ainda superior àquela das doenças 
infecciosas. Essa indagação, formulada por Pinell (2011), requeria a realização de um estudo sócio-histórico. Diversos processos sociais concomitantes que iam da ação filantrópica de segmentos das classes dominantes - as viúvas - à constituição de uma especialidade médica - a cancerologia - ao lado das lutas ao interior do campo médico e científico francês, confluíram para a constituição de um espaço social de luta contra o câncer, que resultou na incorporação, pelo Estado, dessa questão como um problema relevante de saúde, naquele momento histórico, com ações voltadas para o seu controle.

De modo semelhante, a explicação sobre as razões do surgimento de uma política de controle para a aids, no final da década de 1980, no Brasil, mesmo diante da ausência de evidências sobre a sua magnitude e antes da descoberta de um tratamento efetivo, foi possível apoiada em análise histórica. (BARROS, 2013) O espaço aids constituiu-se historicamente como espaço de luta pela organização da resposta à epidemia e de intervenção sanitária. Estavam em disputa a autoridade de falar sobre o significado da doença, suas formas de prevenção e tratamento, e estratégias para o controle da epidemia. A sua composição envolvia indivíduos com inserções diferenciadas em vários campos sociais como médicos, gestores e militantes do movimento homossexual. As peculiaridades da resposta governamental, nesse caso, foram esclarecidas por estudo sobre sua sociogênese. No caso da aids, houve uma inversão no caminho usual de formulação de outras políticas de saúde no Brasil, onde inicialmente o MS elaborava uma política nacional, seguida e operacionalizada pelos estados. As primeiras iniciativas ocorreram em São Paulo, logo após a divulgação de casos de aids no país, em um momento onde o MS negava a necessidade de intervenção. São Paulo, no início dos anos 1980, durante o governo Montoro, possuía uma gestão com caráter democrático e modernizador; uma estrutura de serviços de saúde organizada desde a década de 1960, inclusive com a carreira de sanitarista; um movimento homossexual organizado e qualificado, com lideranças com elevado volume de capital econômico e social que demandaram uma resposta do Estado à epidemia 
que se instalava. Além disso, tinha à frente da Divisão Estadual de Dermatologia Sanitária, ao interior da qual já estava se organizando um Programa de Doenças Sexualmente Transmissíveis, um médico, sanitarista e ex-militante do movimento homossexual. (BARROS; VIEIRA-DA-SILVA, 2016)

Já a política nacional foi implantada posteriormente, a partir de 1985. Foram condições para a formulação de uma política específica para a aids: o processo de transição democrática; a chegada de sanitaristas a cargos de chefia no MS; a rápida evolução da epidemia; a existência de grupos de pesquisa em doenças infecciosas e parasitárias, com patologistas que se converteram em imunologistas; os avanços no campo médico sobre a doença e o estágio de desenvolvimento da pesquisa clínica e laboratorial; a organização por alguns estados de programas de aids; e a pressão exercida por movimentos sociais e imprensa. (BARROS, 2013)

A compreensão das razões históricas para a elaboração dessa política, bem como a análise das trajetórias dos agentes e das lutas comuns ao espaço aids e ao espaço da Saúde Coletiva, ${ }^{3}$ evidenciaram empiricamente a relação da política com o movimento da reforma sanitária e seus pressupostos. Seu surgimento em um momento de ascensão do movimento sanitário e ausência de terapia específica contribuíram para a priorização inicial da prevenção. Por outro lado, a dominância do campo médico e a constituição do Sistema Único de Saúde (SUS) contribuíram para uma articulação entre as medidas preventivas e a garantia do tratamento, componente necessário para a formulação de uma política baseada na integralidade das ações, reconhecida internacionalmente como exemplar. (BARROS, 2013)

Dessa forma, investigar a emergência de uma política de saúde corresponde não apenas a indagar sobre quem, quando, onde e como foi formulada determinada política, mas envolve também a

O estudo sobre a gênese sócio-histórica da Saúde Coletiva brasileira não reuniu evidências que permitissem caracterizá-la como campo consolidado, no sentido de Bourdieu, mas sim de um espaço social que possuía um projeto de tornar-se campo. (VIEIRA-DASILVA, 2015; VIEIRA-DA-SILVA; PINELL, 2014) 
busca dos porquês, da lógica da sua constituição. Essa apreensão requer a análise da estrutura e da dinâmica de um espaço de relações entre agentes sociais (profissionais de saúde, pesquisadores, usuários, gestores, entre outros) que compartilham interesses sobre o objeto da política. Assim, no caso do estudo sobre a gênese da política de controle da aids no Brasil, correspondeu a identificar quem se interessava pela aids e por quê, o que estava em disputa no espaço aids, e porque foi possível que os agentes envolvidos com a formulação da política desenvolvessem um programa orientado pela integralidade do cuidado e universalidade da assistência, nos anos 1990, no Brasil. (BARROS, 2013)

\section{Alguns conceitos centrais: espaço social, campo, habitus, illusio e agentes}

Preliminarmente, diante dos seus diferentes significados, é necessário explicitar o sentido aqui atribuído à política e à política de saúde. (PINTO; VIEIRA-DA-SILVA; BAPTISTA, 2014) Política será aqui compreendida como ação Estatal seguindo análise de Weber (1982) e, mais especificamente, no sentido que lhe é dado por Paim (2003), segundo o qual política de saúde corresponde à ação ou omissão do Estado diante de determinado problema de saúde.

Em segundo lugar, cabe uma explicação para o uso preferencial do conceito de espaço social para designar o microcosmo eventualmente constituído para a formulação de uma política de saúde. $\mathrm{Ou}$ seja: o que se quer dizer com espaço de relações em torno de determinada política? Um dos conceitos centrais na teoria das práticas de Bourdieu é o de campo, que foi progressivamente desenvolvido por aquele autor, apoiado em diversos estudos empíricos sobre universos sociais diferentes como a alta costura, o campo literário, o campo científico, o campo burocrático entre outros. (BOURDIEU, 1996a) Um campo seria um microcosmo relativamente autônomo, uma rede de relações entre agentes e instituições dotados de um habitus 
e de uma illusio comuns. Habitus ${ }^{4}$ aí usado no sentido de sistema de disposições estruturadas e estruturantes das práticas sociais e illusio como investimento e interesse nas questões em jogo no campo. (BOURDIEU, 1996a, 2009)

O vocábulo "campo" é empregado na língua portuguesa com inúmeras finalidades, ${ }^{5}$ como sinônimo de área, setor entre outros. Em Bourdieu (1996a, p. 28), todavia, seu uso como categoria teórica para explicar o mundo social envolve uma analogia com a da física, mais especificamente do chamado "meio newtoniano", cuja objetivação pode se dar, entre outros recursos, através do emprego da análise de correspondências, ${ }^{6}$ que, segundo este autor, corresponde a uma técnica estatística relacional, ou seja, capaz de apreender as relações entre os agentes e permitir a objetivação da sua estrutura. (BOURDIEU, 2006)

Para Bourdieu (2000, p. 41), “[...] um campo é um campo de forças e um campo de lutas para transformar essas relações de força”, sendo a sua estrutura o resultado das disputas ocorridas entre agentes que ocupam posições diferentes definidas pelo volume global de capital bem como pela sua composição. O campo é um espaço de constituição de habitus específicos, sendo uma das suas características, a sua autonomia relativa a outros campos. Autonomia para estabelecer suas regras próprias de consagração e exclusão de objetos e agentes. O estudo empírico de um campo requer a análise da sua sociogênese, a partir da qual poderão ser identificadas as questões que estão em jogo, em disputa, suas lógicas internas, sua arquitetura (polos dominantes e dominados e as oposições em cada polo), a construção de

Sobre os conceitos de "campo", habitus e illusio ver: Bourdieu (1996 a, 2009).

5 O Dicionário Houaiss da Língua Portuguesa apresenta 19 substantivos e 51 locuções. Disponível em: <http://houaiss.uol.com.br/busca?palavra=campo>.

6 Nesse modelo, "as variáveis ativas são aquelas que servem para construir o espaço, ou seja, para definir a distância entre indivíduos e determinar os eixos. As variáveis suplementares intervem a posteriori para caracterizar os eixos". (LEBARON, 2015, p. 48, tradução nossa) 
sua autonomia relativa ${ }^{7}$ e seus nomotetas - os criadores de normas. A noção de subespaços auxilia na compreensão de princípios de diferenciação existentes na conformação dos campos e dos espaços sociais, correspondendo ao surgimento de lógicas específicas, como é o caso do espaço da Saúde Coletiva que se encontra permeado pelos subespaços burocrático, político e científico.

Cabe destacar ainda que, se todo campo social é também um espaço social, ocorre que nem todo espaço social é dotado de autonomia. Todavia, essa noção de espaço tem contribuído na análise de dinâmicas sociais importantes - inclusive aquelas que resultam em políticas -, mas que não chegam a lograr um grau de autonomia ao ponto de se constituir, no sentido bourdieusiano, em um campo específico. Sua viabilização e características se dão frequentemente como resultante do encontro entre agentes situados em um ou mais campos, portanto dotados de habitus e disposições diferentes, mas que possuem em comum o interesse pela política em tela. A trajetória dos agentes envolvidos lhes confere as condições materiais e 24 simbólicas que explicam os seus pontos de vista, a partir do conjunto de seus capitais ${ }^{8}$ que tanto influenciam nos princípios de diferenciação, como têm seu valor significado e resignificado de acordo com as especificidades de cada campo. ${ }^{9}$ (BOURDIEU, 2006)

Nos espaços novos criados na história da construção de um problema de saúde como problema social e sua entrada na agenda do Estado como política de saúde (isto é: a dinâmica social que leva um problema particular a se constituir em um problema do Estado,

7 Em As regras da arte: gênese e estrutura do campo literário, Bourdieu (1996a) identifica a construção desse campo na França justamente com a conquista de sua autonomia em relação ao campo econômico.

8 Capitais são, para Bourdieu (1984a, p. 3), "[...] poderes que definem as possibilidades de obtenção de benefícios em um campo determinado".

9 Bourdieu (2006, p. 107) explica que, "[...] sendo o capital uma relação social, ou seja, uma energia social que existe e produz seus efeitos apenas no campo em que ela se produz e se reproduz, cada uma das propriedades associadas à classe recebe seu valor e sua eficácia das leis específicas de cada campo". 
ao ponto de desencadear uma política), os capitais adquiridos por cada agente vão funcionar segundo a hierarquia dos campos que estão envolvidos com uma dominância do capital burocrático, tendo em vista que as decisões finais são formalizadas nesse nível, mas também do capital político. $\mathrm{O}$ fato de David Boianovsky ser um médico, especialista em nutrição, professor universitário e pesquisador foi importante para sua participação no Pifat/PAT. Todavia, todo seu capital técnico e social precisou ser convertido em capital burocrático, mediado pelo alto capital político do MT à época, para que ele pudesse coordenar o programa. Ainda assim, como era um "novato" no campo burocrático, terminou prevalecendo no desenho da política os pontos de vista de outros agentes com maior tempo de pertencimento ou articulação com o campo burocrático. E isso auxilia a compreender porque o Pifat/PAT foi de um jeito e não de outro. (SOUZA, 2013)

O fato de José Sarney ter apresentado o projeto de lei sobre a aids, ${ }^{10} \mathrm{em}$ uma primeira aproximação, poderia autorizar a atribuição, apenas a esse político, do mérito pela iniciativa, por razões quiçá de ordem pessoal, como especulado por alguns informantes. (NUNN, 2009) No entanto, a análise histórica mostrou a complexa teia de inter-relações ocorridas no espaço aids entre o sociólogo Betinho, o médico sanitarista e deputado federal pelo Rio de Janeiro, Sérgio Arouca, e o ex-ministro da saúde e, na época, chefe de gabinete do senador José Sarney, Carlos Corrêa de Menezes Sant'anna, que resultaram no encaminhamento do projeto de lei por ele. (BARROS, 2013)

Dessa forma, estudos específicos sobre políticas de saúde têm revelado que, em torno da construção social do problema e da formulação das ações estatais, que serão a posteriori caracterizadas como políticas, principalmente em decorrência da sua formalização em planos e programas, está um espaço de relações entre agentes oriundos de campos diferentes.

10 Em 1996, o então senador José Sarney apresentou o Projeto de Lei do Senado n. ${ }^{\circ} 158$, que dispunha sobre a distribuição gratuita de medicamentos aos portadores de HIV/aids. 
Assim, Pinell (2002) caracterizou o espaço associativo ao interior do qual a resposta à epidemia da aids foi construída na França, nos anos 1980 e 1990 como "espaço aids", tendo como principais agentes militantes homossexuais, mas com uma autonomia relativa em relação aos movimentos homossexuais, e médicos engajados no tratamento dos primeiros doentes. Também no Brasil, pôde ser caracterizado um espaço aids, que, no período da gênese da política nacional, era formado por agentes oriundos dos campos científico, burocrático e médico e também dos movimentos homossexuais. (BARROS, 2013) No espaço aids nos dois estudos, embora os diversos agentes possuíssem interesses comuns referentes ao mesmo problema social, possuíam representações diferentes a respeito da doença e tinham pontos de vista também distintos em relação as estratégias de screening, prevenção e tratamento.

A análise desses espaços específicos de formulação das políticas ganha assim uma complexidade adicional. $\mathrm{O}$ estudo empírico de um campo por si só já requer a adoçãode uma perspectiva relacional.

26 Em outras palavras, busca analisar o sistema de relações objetivas nas quais os indivíduos estão inseridos e as tomadas de posição, influenciadas pelas posições ocupadas e pelas trajetórias. (BOURDIEU, 1996a) Dessa forma, além do estudo do espaço específico de construção da política de saúde, o investigador precisa explorar o estado do campo onde os agentes envolvidos têm sua inserção principal.

A compreensão da natureza tributária do Pifat/PAT, e as razões desse programa ter ficado alocado no MT e não no MS, só se revelaram quando se fez a análise das trajetórias de agentes, que a literatura sobre o PAT ignorava (ou "esquecera"): nomes ligados ao grande empresariado paulista e à "Administração de Recursos Humanos" como Oswaldo Chechia, Luiz Gonzaga Ferreira e Antônio Guimarães. O momento ambíguo do governo Geisel, denominado de "abertura gradual, lenta e segura" da Ditatura Militar, permitiu que o MT se constituísse em espaço de formulação de políticas sociais. Lá encontravam-se esses agentes, executivos de grandes multinacionais, com trânsito no campo burocrático e com alto capital militante. 
Naquele espaço, embora figure como o "pai do PAT”, David Boianovsky se incorporou posteriormente, muito em razão de sua perda de posição no MS, onde chegou a ser cotado para assumir o Instituto Nacional de Alimentação e Nutrição (Inan). Foi desse modo que, para desenvolver o PAT, Boianovsky terminou produzindo um Pifat apoiado em outro programa, já em vigor no MT, coordenado por Luiz Gonzaga Ferreira, não pensado como ações de nutrição, mas destinado ao incentivo fiscal, à construção de escolas e de cursos para a capacitação de trabalhadores. Ou seja: não foi uma "lógica" nutricional ou a expertise do nutrólogo que prevaleceram, mas os pontos de vistas dominantes naquele momento de gênese: financiamento pelo Estado do custo de produção e a reprodução da força de trabalho impulsionados pelo II Plano Nacional de Desenvolvimento (IIPND). (SOUZA, 2013)

O conceito de espaço social também pode ser atribuído a universos sociais que possuem um propósito de constituírem-se em um campo, porém não apresentam ainda todas as características de um campo já consolidado como foi o caso do espaço da Saúde Coletiva no Brasil nos anos 1970. (VIEIRA-DA-SILVA, 2015, VIEIRA-DASILVA; PINELL, 2014) São microcosmos onde, à semelhança de campos consolidados, agentes dotados de diferentes capitais disputam as questões específicas daquele universo social. Porém, a pequena autonomia relativa e a inexistência de habitus específico não permite denominá-los de campo. (VIEIRA-DA-SILVA, 2015)

\section{O conceito de agente das práticas}

O uso do termo "agente das práticas", embora não sistematizado com a precisão encontrada nos demais conceitos ao longo de sua obra, traduz uma das questões centrais do pensamento de Pierre Bourdieu intimamente relacionada à sua teoria das práticas que se opõe às teorias subjetivistas, à teoria da ação racional e às concepções que priorizam as determinações externas, econômicas ou não. 
Está relacionado aos seus outros conceitos de campo, habitus e illusio ao interior dos quais ganha sentido.

O conceito de "agentes" se opõe tanto à ideia de "sujeito-criador", subjetivamente autônomo e orientado, dotado de um projeto, quanto às determinações estruturais que definem o curso da ação de forma mecânica. Também esse conceito opõe-se à ideologia do ator racional que busca a origem dos atos em uma intenção da consciência e associa-se a uma visão estreita da racionalidade das práticas. (BOURDIEU, 2009) Para ele, o ator não é mais que a "projeção imaginária do sujeito culto no agente atuante”, sendo que a teoria da ação racional "somente reconhece as respostas racionais de um agente sem história" e corresponderia "à escolha livre de um ator livre de todo o condicionamento social e econômico". (BOURDIEU; WACQUANT, 1992, p. 98-99, tradução nossa)

No estruturalismo, a noção de agente histórico, atuante na estrutura, é subsumida pela noção que é a própria estrutura, subjacente às relações sociais, que desempenha esse papel de produção e reprodução da ordem social. As estruturas e abstrações e mesmo os conceitos são interpretadas como sujeitos.

O discurso objetivista tende a constituir o modelo construído para explicar as práticas como um poder realmente capaz de determiná-los: reificando as abstrações (em frases como a 'cultura determina a idade do desaleitamento...') ele trata suas construções como 'cultura', 'estruturas', 'classes sociais' ou 'modos de produção' como realidades dotadas de eficácia social, capaz de constranger diretamente as práticas; ou então atribuindo aos conceitos o poder de agir na história [...] ele personifica os coletivos e os transforma em sujeitos responsáveis de ações históricas.(BOURDIEU, 2009, p. 62)

Bourdieu (2009) reconhece, da teoria estruturalista, que existem estruturas objetivas, independentes da consciência e da vontade dos agentes. Entretanto, para esse autor, existe uma dialética entre as estruturas objetivas e as estruturas incorporadas sob a forma de habitus, 
que ocorre em cada ação concreta. Os habitus, por sua vez, são produto das histórias individuais e das histórias coletivas. São esquemas de percepção, de pensamento e de ação dos agentes - como estruturas mentais produto de uma gênese social. Dessa forma, há uma interiorização do social pelos agentes por meio do habitus, princípio gerador de representações e práticas, vinculados às logicas de classe e de campo e da posição nele ocupada pelos agentes. (BOURDIEU 2009)

$\mathrm{O}$ conceito de agente não evidencia uma ação humana livre de contingências, uma vez que se encontra influenciada pela "estrutura estruturada" do campo, por suas regularidades e lógicas, e pelo seu sentido de jogo. $\mathrm{O}$ agente é aquele que age e luta dentro de um campo de interesses, tendo em sua ação princípios e inculcações dessas lógicas que lhe são imanentes produzidas no encontro das histórias individuais dos agentes com a história coletiva do campo. Os agentes movem-se no campo, dotados de um senso prático, um sistema adquirido de preferências, de classificações, de percepção. (BOURDIEU, 1996a)

Dessa forma, para Bourdieu e Wacquant (1992), o uso do conceito de agente não é um mero substituto dos conceitos de sujeito ou de ator. Integra sua teoria sobre o mundo social, segundo a qual para se compreender as representações sociais e as práticas sociais é necessário investigar os campos e os espaços sociais onde essas práticas se realizam como o produto do encontro de duas histórias: a história incorporada nos indivíduos sob a forma de habitus e a história incorporada nas coisas sob a forma de estruturas. Assim, conclui que o objeto próprio da ciência social não é nem o indivíduo nem os grupos, mas a dialética entre o campo, o habitus e a illusio. (BOURDIEU, 2009; BOURDIEU, WACQUANT, 1992) ${ }^{11}$

11 A esse respeito, Bourdieu (1990, p. 45) chega a considerar a oposição entre indivíduo e sociedade como absurda, "[...] oposição que a noção de habitus enquanto social incorporado, logo, individuado, visa superar." Para que essas afirmações não pareçam arbitrárias, recomenda-se a leitura dos trabalhos empíricos nos quais essa dialética fica evidenciada, particularmente o livro As regras da arte. (BOURDIEU, 1996a) 


\section{A articulação entre a análise das trajetórias e as condições históricas de possibilidade}

A apreensão empírica da dialética acima referida é complexa e requer a mobilização de diversas técnicas de objetivação e análise qualitativas e quantitativas. Ademais, toda metodologia depende da problemática de pesquisa, do momento histórico e das fontes disponíveis. Como falar em técnicas dissociadas do objeto é contraproducente, remetemos o leitor aos trabalhos empíricos que fizeram uso das mesmas.

Apenas alguns comentários sobre a relação entre a análise das trajetórias e as condições históricas de possibilidade. $\mathrm{O}$ conceito de trajetória em Bourdieu diferencia-se tanto da ideia de biografia como também não corresponde a uma modalidade de história oral. (BOURDIEU, 2006) As trajetórias possíveis, em um determinado campo, correspondem à direção que as forças que atuam no campo imprimem aos agentes, que por sua vez contribuem para a criação de polos resultante dessas trajetórias. São as posições construídas e ou ocupadas pelos agentes ao longo da vida. Na criação do campo artístico, as trajetórias de Flaubert, Manet e Baudelaire constroem essas possibilidades históricas, sendo que esses precursores inventaram o polo da arte pela arte, em contraposição à arte burguesa e o mercado por um lado, e a arte engajada por outro. (BOURDIEU, 1996a) Já na gênese do espaço da Saúde Coletiva, nos anos 1970, as trajetórias de Sérgio Arouca e Hésio Cordeiro, em um sentido, e de Cecília Donnangelo, por outro, marcaram polos importantes de desenvolvimento posterior do espaço nas áreas de Ciências Sociais em Saúde e das políticas de saúde que se distinguiam da medicina preventiva, da saúde publica tradicional e mesmo da epidemiologia clássica. Essas trajetórias foram possíveis em decorrência da conjunção de processos históricos concomitantes, tais como as contradições da conjuntura nacional e o financiamento das fundações americanas que permearam as histórias de vida desses agentes e da rede de relações criadas entre docentes de departamentos de medicina 
preventiva, militantes da luta democrática e pesquisadores inovadores. (VIEIRA-DA-SILVA, 2015)

A distribuição dos agentes no espaço social é dada pelo volume de capital de diferentes espécies, como o capital cultural, o capital econômico, o capital político, o capital simbólico, bem como outros tipos de capital específicos de cada campo, e a trajetória social dos agentes. (BOURDIEU, 1996a) A existência dessas diversas formas de capital corresponde justamente à "multiplicidade de universos socialmente diferenciados”. (PINTO, 1998, p. 215) A classificação de algumas dessas espécies de capital pode ser feita a partir da adaptação da matriz utilizada nos trabalhos desenvolvido por Vieira-daSilva e Pinell (2014) e Vieira-da-Silva (2015) inspirada nas objetivações de Bourdieu (1984b) no Homo academicus. Essas objetivações, contudo, variam a depender do momento histórico estudado, bem como das especificidades do objeto de estudo. (BARROS, 2013; FURTADO, 2014; SOUZA, 2013) Ademais, as posições e trajetórias podem corresponder a tomadas de posição que auxiliam na compreensão da estrutura do campo bem como nas questões que 31 estão em jogo.

A análise da trajetória dos agentes identificados em cada caso pode ser realizada a partir de entrevistas em profundidade e ou através de biografias. Já as condições históricas de possibilidade, a depender do objeto, podem apoiar-se em fontes bibliográficas e documentais. Em ambos os casos, a consulta a fontes primárias traz qualidade a qualquer estudo histórico, tendo em vista a variedade dos pontos de vista existentes sobre qualquer aspecto do mundo social. A inclusão de agentes em posições menos destacadas auxilia na compreensão do significado das posições dominantes e dominadas ao interior do espaço social a ser estudado.

A recuperação das trajetórias pode ser feita ou por entrevistas ou por biografias a depender do momento histórico investigado. Ressalta-se o cuidado necessário com a forma que as informações são construídas, a maneira de apreender a realidade da qual as informações são produto. Ou seja, o comportamento do entrevistador, sua 
maneira de se apresentar e de apresentar a entrevista, suas questões e silêncios, reforços e encorajamentos, são indicações e intervenções que orientam os propósitos e estruturam a entrevista. (BOURDIEU, 2006) Sobre a técnica de entrevista, Bourdieu (1991, p. 3) diz que

[...] trata-se de uma forma de escuta ativa e armada demandando uma postura aparentemente contraditória: de um lado uma disponibilidade total para a pessoa interrogada, uma submissão inteira à singularidade de seu caso particular, que pode conduzir, por um tipo de mimetismo mais ou menos controlado, à adotar sua linguagem e à entrar nas suas visões, nos seus sentimentos, nos seus pensamentos; de outro, um interrogatório metódico, forte no conhecimento das condições objetivas, comuns a toda uma categoria, e atenta aos efeitos de relação de entrevista.

O pesquisador, portanto, apoiado no referencial teórico, vai olhar para o objeto de estudo buscando dar razão, buscando compreender o seu processo histórico de construção e desenvolvimento, a trajetória dos agentes envolvidos, as estruturas objetivas e mentais criadas, e a dinâmica das relações estabelecidas, sempre na tentativa de articular o material e o simbólico.

As entrevistas são fundamentalmente recurso para a análise das sucessivas posições ocupadas pelos agentes, afim de explorar suas tomadas de posição, bem como para a localização de documentos raros e acervos pessoais. $\mathrm{O}$ confronto da história oral com fontes documentais aumenta a validade das conclusões. A esse respeito são diversas as fontes históricas que podem ser acionadas a exemplo de documentos oficiais (leis, decretos, normas, pareceres), técnicos (relatório, planos, teses) ou documentos pessoais (cartas, testamentos, inventários, autobiografias, fotografias). A crítica das fontes é de fundamental importância, pois elas não falam por si e precisam ter sua validade analisada. 


\section{A amnésia da gênese}

Segundo Bourdieu (2012), o processo de institucionalização tende a fazer esquecer as disputas iniciais, as alternativas possíveis que foram vencidas. Por isso, é importante voltar aos conflitos das origens e apreender os possíveis que se realizaram e também os possíveis excluídos. Para o autor, esse é um dos instrumentos de ruptura com o senso comum mais poderosos. A análise histórica, ao identificar os confrontos dos primeiros momentos, permite perceber as possibilidades do que poderia ter acontecido, criando alternativas para transformações sociais por meio dessa "utopia prática". ${ }^{12}$ (BOURDIEU, 2006) Como exemplo, este autor refere-se à homogeneização da escritura, da ortografia e da maneira de falar como fruto do processo de construção de Estado que, motivo de disputas em sua gênese, vai paulatinamente, geração após geração, incorporandose até tornar-se inconsciente. (BOURDIEU, 2012)

No caso do Pifat/PAT, um dos efeitos mais marcantes da amnésia da gênese foi justamente considerá-lo apenas como uma ação, um programa destinado à alimentação do trabalhador (PAT), fruto de uma racionalidade técnica operada pelo Estado brasileiro visando intervir no estado nutricional dos seus usuários. No entanto, isso não passa de um artefato. $\mathrm{O}$ estudo sociogenético do espaço evidenciou justamente o contrário: enquanto a dimensão nutricional passou a ser operada no interior do campo econômico, nas negociações entre empregadores, empregados e empresas de refeições coletivas ou tíquetes, ao Estado coube o custeio da intervenção. (SOUZA, 2013)

12 Nas palavras daquele autor: "E assim, ao revelar os possíveis mortos, permite-se reatualizar os conflitos iniciais e a possibilidade de que houvesse sido (e de que seja) de outro modo e, por meio dessa utopia prática, recoloca em questão o possível que se concretizou entre todos os outros". (BOURDIEU, 2006, p. 98) 


\section{Os possíveis mortos}

Uma segunda consequência do retorno às origens, segundo Bourdieu, é a identificação das possibilidades que não se realizaram - os possíveis mortos. Geralmente as construções históricas são tratadas como algo que deveria acontecer e não como um entre alguns possíveis realizáveis em determinado momento histórico. Ao longo do tempo, as escolhas do passado transformam-se em coerções objetivadas e incorporadas, restringindo o universo de possíveis realizáveis, de modo que alguns possíveis são completamente esquecidos. Ou seja, as alternativas que existiam naquele momento histórico são esquecidas, sepultadas. “O espaço dos possíveis não pára de se fechar a cada momento, [...] a história elimina os possíveis e os faz esquecer como possíveis, que ela torna mesmo impensáveis os possíveis.” (BOURDIEU, 2012, p. 187)

Bourdieu cita como exemplo um projeto de lei do parlamento francês nos anos 1990 que buscava criar um monopólio no campo jurídico aos portadores de diploma, explicando que, uma vez aprovado, levaria a mudanças nas estruturas objetivas (desaparecimento dos plantões jurídicos prestados por não diplomados a mulheres e desfavorecidos), de modo que, em alguns anos, o possível alternativo (existência de plantões jurídicos assegurados por não profissionais) seria esquecido. Ou a estrutura poderia mudar e as associações garantiriam a formação desses indivíduos, ou os tribunais trabalhistas poderiam ter sua dinâmica alterada, alterando também as estruturas mentais. Ou o caso da política da habitação francesa, onde

[...] a alternativa entre HLM ${ }^{13}$ coletivos ou casinhas particulares é uma falsa alternativa; há uma terceira possibilidade, a das casinhas para aluguel, que não existe. Não há um sociólogo que fale disso [...] Ou seja, a alternativa, a oposição habitat coletivo/individual é varrida por um processo histórico que constituiu o problema sob essa

13 Do francês, Habitation à Loyer Modéré, ou habitação de baixa renda. 
forma cuja genealogia podemos fazer. E há milhares de problemas desse tipo. (BOURDIEU, 2012, p. 190-191)

No que se refere ao Pifat/PAT, a conformação original do espaço resultou em, ao menos, dois "possíveis mortos" - propostas originais que não conseguiram ser viabilizadas quando o espaço se fechou: a concessão de financiamentos para construção de restaurantes por instituições civis de empregados ou empregadores; e o cadastro de restaurantes comerciais para oferecer diretamente as refeições aos trabalhadores e sem a intermediação das empresas de tíquetes. Aliás, embora essas empresas operassem desde o início do programa, sua atuação só foi regulamentada em 1991. (SOUZA, 2013)

Também a distribuição de medicamentos antirretrovirais pelo MS não era uma proposta inicial. Mas a possibilidade de implementação de uma política de controle da aids no Brasil sem acesso a antirretrovirais, seguindo as recomendações das agências internacionais para países em desenvolvimento, pode ser considerada um "possível morto”. A lei n. ${ }^{\circ}$ 9.313/1996 garantiu o acesso universal a medicamentos para o tratamento da aids, sepultando essa alternativa. (BARROS, 2013)

O projeto da Reforma Sanitária Brasileira conforme proposição dos seus fundadores incorporada pela VIII Conferência Nacional de Saúde apoiada em uma teoria social da saúde que identificava determinantes sociais para a produção da saúde-doença e requeria mudanças estruturais para a sua resolução pode ser considerado como um possível morto. (VIEIRA-DA-SILVA, 2015) Era parte do espaço de possíveis naquele momento histórico. Aquele espaço de possíveis fechou-se parcialmente com a correlação de forças presente na Constituinte de 1988 e posteriormente mais ainda com o retrocesso do governo Collor. 


\section{Considerações finais}

A análise sócio-histórica de políticas de saúde, apoiada na sociologia reflexiva e genética de Pierre Bourdieu, constitui-se em abordagem capaz de orientar investigações sobre políticas de saúde de forma fecunda e inovadora, vindo a somar-se ao conjunto de perspectivas metodológicas existentes para a análise política em saúde. Isso não quer dizer que os pesquisadores que tomam por objeto as políticas devam converter-se em historiadores ou vice-versa. Também não significa que somente poderá ser realizada por meio de uma equipe multidisciplinar. Sendo um objeto que requer a mobilização de saberes de diversas disciplinas, impõe, além do necessário diálogo entre pesquisadores com formações diferenciadas, uma apropriação transdisciplinar desse conhecimento. Se os problemas da atualidade podem ser eventualmente necessários para orientar uma pesquisa histórica relevante, o oposto é sistematicamente verdadeiro: o recuo histórico adequado esclarece dilemas e questões do momento presente.

A tentativa de aclarar alguns conceitos-chave da sociologia bourdieusiana por meio de exemplos extraídos, tanto das suas pesquisas empíricas como das investigações desenvolvidas pelos autores do presente ensaio, corresponde a uma tentativa de pôr em prática sua epistemologia onde os conceitos teóricos não fazem sentido dissociados dos estudos de realidades concretas. (BOURDIEU, 1992) Também nos pareceu necessária essa explicitação conceitual, dado que alguns de seus conceitos centrais já se converteram em senso comum douto, a exemplo do conceito de campo, ou ainda provocam reações de estranheza como o conceito de agente das práticas. No primeiro caso, foi necessária a distinção entre os conceitos de campo e espaço social, bem como a recuperação das origens do conceito que Pierre Bourdieu (1992) foi construindo pouco a pouco, por meio de suas pesquisas empíricas sobre o campo literário, o campo da alta costura, o campo científico, o campo burocrático - só para citar as mais importantes. 
Os estudos sócio-históricos, conforme vimos neste capítulo, podem ajudar na compreensão do processo social que envolve a constituição de pontos de vista dominantes, pretensamente universais, sobre um dado problema em análise. Esse tipo de análise favorece, portanto, a identificação de formas de apropriação, legitimação e dominação ao interior de espaços sociais, como no caso das políticas de saúde assumidas como intervenção do Estado. Revelar contradições e conflitos é parte do trabalho da análise da gênese das políticas de saúde, cuja formalização tende a se apresentar de modo suficientemente ambivalente, acomodando as assimetrias e neutralizando as tensões e os interesses conflitivos das quais resultaram, para então operar com uma lógica própria, constituindo seu mercado específico com agentes dotados de legitimidade em torno de uma causa defendida ou aceita por todos.

A análise sócio-histórica das políticas de saúde de orientação bourdieusiana não corresponde a um fechamento monoautoral. Implica na aderência a uma epistemologia de inspiração bachelardiana do "não", no exercício da dúvida radical. (BOURDIEU 1989) Impõe ainda um diálogo com outros pesquisadores e teóricos atuais e contemporâneos que trataram do objeto de investigação. É claro que esse diálogo tem limites diante da magnitude e extensão do conhecimento contemporâneo. Em decorrência, a seleção das fontes relevantes é sempre um exercício complexo, com as limitações dadas pelo estado atual do espaço da saúde coletiva, do campo científico e da posição que os autores ocupam nesses espaços. Portanto, sujeita a críticas e retificações.

\section{Referências}

BACHELARD, G. A formação do espírito científico: contribuição para uma psicanálise do conhecimento. Rio de Janeiro: Contraponto, 1996.

BARROS, S. G. A política nacional de luta contra a aids e o espaço aids no Brasil. 2013. 274 f. Tese (Doutorado em Saúde Coletiva) - Instituto de Saúde Coletiva, Universidade Federal da Bahia, Salvador, 2013. 
BARROS, S. G. de; VIEIRA-DA-SILVA, L. M. The genesis of the AIDS policy and AIDS Space in Brazil (1981-1989). Revista de Saúde Pública, São Paulo, v. 50, n. 43, p. 1-12, 2016.

BOURDIEU, P. A distinção: crítica social do julgamento. São Paulo:

Edusp; Porto Alegre: Zouk, 2006.

BOURDIEU, P. As regras da arte: genese e estrutura do campo literário. Lisboa: Presença, 1996a.

BOURDIEU, P. Coisas ditas. São Paulo: Brasiliense, 1990.

BOURDIEU, P. Razões práticas: sobre a teoria da ação. Campinas:

Papirus, 1996b.

BOURDIEU, P. Espace social et genèse des classes. Actes de la recherche en sciences sociales, Paris, v. 52, n. 1, p. 52-53, 1984a.

BOURDIEU, P. Homo academicus. Paris: Ed. minuit, 1984b.

BOURDIEU, P. Introduction à la socioanalyse. Actes de la recherche en sciences sociales, Paris, v. 90, n. 1, p.3-5, déc. 1991.

38 BOURDIEU, P. La noblesse d'état: grandes écoles et esprit de corps. Paris: Les Éditions de Minuit, 1989a.

BOURDIEU, P. O poder simbólico. Rio de Janeiro: Bertrand Brasil;

Lisboa: DIFEL, 1989b.

BOURDIEU, P. O senso prático. Petropolis: Vozes, 2009.

BOURDIEU, P. Propos sur le champ politique. Lyon: Presse Universitaire de Lyon, 2000.

BOURDIEU, P. Sur l'État - cours de collège de france: 1989-1992. Paris:

Raisons D'agir: Seuil, 2012.

BOURDIEU, P.; CHAMBOREDON, J. C.; PASSERON, J. C. A profissão do sociólogo: preliminares epistemológicas. Petrópolis: Vozes, 1999.

BOURDIEU, P.; WACQUANT, L. J. D. Réponses: pour une anthropologie réflexive. Paris: Seuil, 1992.

BRASIL. Lei n. 6.321, de 14 de abril de 1976. Dispõe sobre a dedução, do lucro tributável para fins de imposto sobre a renda das pessoas jurídicas, 
do dobro das despesas realizadas em programas de alimentação do trabalhador. Diário Oficial [da] Republica Federativa da Brasil. Brasília, DF, 19 abr. 1976.

CHAMPAGNE, P.; CHRISTIN, O. Pierre Bourdieu: une initiation. Lyon: Presses Universitaires de Lyon, 2012.

FREYRE, G. Casa-grande ఓ senzala. 34. ed. Rio de Janeiro: Record, 1998. cap. 4.

HOCHMAN, G. História e Políticas publicas: a política pública como campo multidisciplinar. E. MARQUES, E.; FARIA, C. A. P. (Org.). A política pública como campo multidisciplinar. São Paulo: Unesp; Rio de Janeiro: Ed. Fiocruz, 2013.

LEBARON, F. L'espace social:statistique et analyse géométrique des données dans l'ouvre de Pierre Bourdieu. In: LEBARON, F.; ROUX, B. L. (Org.). La méthodologie de Pierre Bourdieu en action: espace culturel, espace social et analyses des données. Paris: Dunod, 2015.

NUNN, A. The politics and history of AIDS treatment in Brazil. New York: Springer Science, 2009.

PAIM, J. S. Políticas de saúde no Brasil: epidemiologia e saúde. In: ROUQUAYROL, M. Z.; ALMEIDA FILHO, N. Epidemiologia \& Saúde. Rio de Janeiro: MEDSI, 2003. p. 587-603.

PINELL, P. Análise sociológica das políticas de saúde. Rio de Janeiro: Ed. Fiocruz, 2010.

PINELL, P. Une épidémie politique:la lutte contre le sida en France, 1981-1996. Paris: Presses Universitaires de France, 2002.

PINELL, P. O nascimento das Políticas contra o Cancer na França. In: PINELL, P. Analise sociológica das políticas de saúde. Rio de Janeiro: Ed. Fiocruz, 2011.

PINTO, I. C.;VIEIRA-DA-SILVA, L. M.; BAPTISTA, T. V. F. Ciclo de uma política, política pública, política social e política de saúde. In: PAIM, J.S.; ALMEIDA-FILHO, N. (Org.). Saúde coletiva: teoria e prática. Rio de Janeiro: MedBook, 2014. p. 69-81. 
PINTO, L. Pierre Bourdieu et la théorie du monde social. Paris: Albin Michel, 1998.

SOUZA, J. C. Avaliação “ex-post” de três programas de intervenção nutricional: Gente da Gente I, Gente da Gente II e Prodea. 1999, 159 f. Dissertação (Mestrado em Interunidades em Nutrição Humana Aplica) Faculdade de Ciências Farmacêuticas da USP, Faculdade de Economia e Administração, Universidade de São Paulo, São Paulo, 1999.

SOUZA, J. C. A gênese do programa de incentivo fiscal à alimentação do trabalhador (PIFAT/PAT). 2013. 261f. Tese (Doutorado em Saúde Coletiva) - Instituto de Saúde Coletiva, Universidade Federal da Bahia, Salvador, 2013.

STEVENS, R. A.; ROSENBERG, C. E; BURNS, L. R. (Ed.). History and health policy in the United States: puting the past back in new brunswick. New Jersey and London: RutgersUniversity Press, 2006.

VIEIRA-DA-SILVA, L. M. Gênese Sócio-Histórica da Saúde Coletiva. In: LIMA, N. T.; SANTANA, J. P.; PAIVA, C. H. A. Saúde coletiva: a Abrasco em 35 anos de história. Rio de Janeiro: Ed.Fiocruz, 2015. p. 25-48.

VIEIRA-DA-SILVA, L.M.; PINELL, P. The genesis of collective health in brazil. Sociology of Health \& Illness, Boston, v. 36 n. 3, p. 432-446, 2014.

WEBER, M. Ensaios de sociologia. Rio de Janeiro: LTC, 1982. 